\title{
Neuro-Fuzzy based Decision Support System for Electrical Cable Production Planning
}

\author{
Olumide Obe \\ Federal University of Technology \\ Akure, Nigeria
}

\author{
Akinyokun Oluyomi \\ Federal University of Technology \\ Akure, Nigeria
}

\author{
Seriki Oluwadamilola \\ Federal University of Technology \\ Akure, Nigeria
}

\begin{abstract}
Overtime the manufacturing industry and information technology (IT) has become intertwined as the electric cable manufacturing bears heavy expectation on IT to achieve its desired goals and commercial competitive advantage through effective and efficient production planning process. Production planning and overcoming its ensuing challenges such as high precision in predicting and meeting demand in a continuously non-stable business environment has become an evolving research area in the field of management sciences. This research therefore offers a neuro-fuzzy decision support system (DSS) for electrical cable production planning. The system consists of database of cable information and adaptive neuro-fuzzy inference system (ANFIS) module. The functionality of this system is tested and validated using preprocessed record of customer orders of Coleman Technical Industries Limited Nigeria and evaluated with standard statistical procedure. The outcome of evaluation proved the proposed system to be $90.06 \%$ accurate in predicting the production plan.
\end{abstract}

\section{General Terms}

Neuro-fuzzy Decision Support System.

\section{Keywords}

Decision Support System, Production Planning, Electrical Cable, Adaptive Neuro-Fuzzy Inference System.

\subsection{INTRODUCTION}

Production is one of the essential activities of an enterprise. It occupies significant position in the manufacturing process while other aspect of management such as financial capital, human resource and marketing revolve around it. This research therefore views Production as the use of money, man, machine and energy to transform raw or crude material into processed or finished product. However, production process could be somewhat complex and tiresome most especially when it involves the need for a high level of precision in demand prediction.

Production Planning is a managerial process that makes sure adequate raw products, human resource and other essential items are available to make finished products within the time specified [1]. Planning and regulating electrical cable manufacturing processes could be complex due to indices which determines the quality and time of delivery of required product. This comprises predicting demand, interpreting the demand forecast and resultantly developing a production plan for the purpose of optimizing the company's objective.

Transmission cable designs are very similar throughout the world though many countries have preferences for a particular design; however, the disparities are not essential. In engineering; economy, technology and practical issues are fairly considered to present the best possible design. For transmission, distribution or utilisation, choice of cable typically falls between overhead cables and underground cables. For economic reasons and except for environmental or other considerations overhead lines are used largely in rural areas However, in urban areas it is more usual to install insulated cables which, in the main, are buried underground. Cable production process involves Drawing and Annealing, Stranding, Insulation, sheathing and armouring and Testing.

\subsection{DECISION SUPPORT SYSTEM (DSS)}

A Decision Support System (DSS); as documented in [33], is the digital interactive system or sub-system developed with the intention of aiding managerial personnel to make use of computing technology, available data, documentations, knowledge base, and models to recognize and proffer solution to identified problems, finish decision process tasks, and resultantly make decisions

The realization of the need to be effective in playing a key role in the globalization of the world economy has brought about increasingly greater demands on modern entrepreneurs. Presently, production planning process is difficult without appropriate tools for demand forecast and decision making at every level of manufacturing [2]. Therefore, to achieve competitive advantage, there is the need to use information systems to drive set goals such as capacity optimization, lead times minimization and flexibility of production. This is referred to as production planning and control system (PPC). Although many production companies use Enterprise Resource Planning systems (ERP) for their enterprise/accounting management, ERP lack DecisionSupport (DS) capabilities, resulting into decrease in efficiency and company competitiveness. Also, the integration of domain knowledge and decision support to these systems will involve a high level of customization and cost which may not be affordable particularly for small and medium scale enterprises (SMEs).

In [3], a DSS using artificial neural networks (ANN) and neuro-fuzzy models for demand forecasting was proposed. The research documented that supply, production, and distribution makes up the three vital levels of supply chain process. The manufacturer and supplier only do not make up the supply chain as supply chain involves mobility, retail, warehousing and the clienteles. Therefore, knowledge, precise information, goods and/or resources amongst these units must be well managed to achieve over-all profit optimization. The flow of information between units is critical to both forecasting in supply management and supply chain's success. Necessary indices to making good decisions include supply forecast, market environment, price and technology. There is need for a technical/mathematical model-based decisionmaking system for establishments in a continuously fluctuating economy. Predicting expected demand of product(s) over a specific period of time is an important target 
in an enterprise as it entails being able to visualize expected demand as precise as possible.

\subsection{Artificial Neural Network (ANN)}

[4] documented that artificial neural network (ANN) serves the purpose of information processing, the fundamental element in an ANN is the neuron. Mathematically, a neuron k is presented as shown in Equations (1) and (2).

$$
\begin{aligned}
& u_{k}=\sum_{j-1}^{p} w_{k j} x_{j} \\
& y_{k}=\varphi\left(u_{k}-\theta_{k}\right)
\end{aligned}
$$

Where $x_{1}, x_{2}, \ldots, x_{p}$ are input signals; $w_{k 1}, w_{k 2}, \ldots$ , $w_{k p}$ are the synaptic weights of neuron $\mathrm{k}$, and, $u_{k}$ is the linear combiner output while $\theta_{k}$ represents the threshold. In addition, $\varphi$ (.) represents the activation function; and $y_{k}$ represents the output signal of the neuron. Each of the neurons is connected to some of its neighbors with varying coefficients of connectivity representing the strengths of these connections. Learning is achieved through regulating their strength for the neurons eventual grouping into layers. At the input layer, neurons obtain input from external environment, while output layer comprises of neurons which communicate the output of the system to the user or external to the environment. Usually, these two layers have a number of hidden layers between them which functions as a "black box" linking the relationship between the input and the output. Unsupervised and Supervised learning make up the two learning method categories.

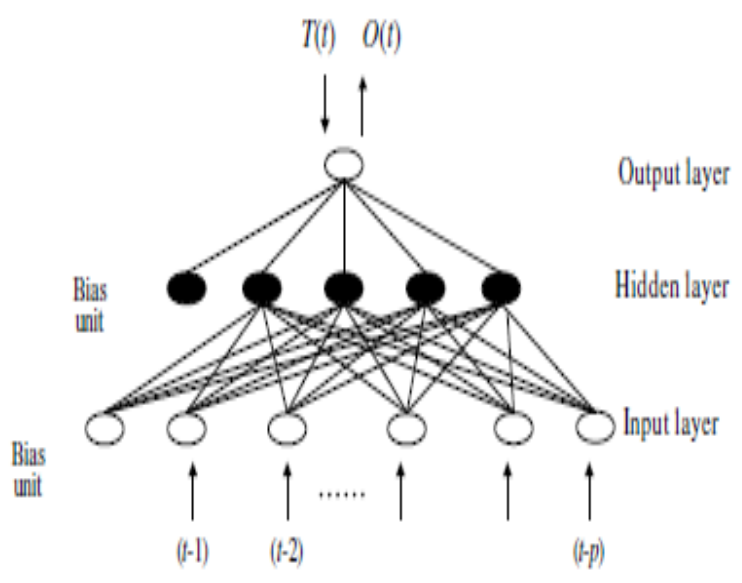

Fig 1: Structure of ANN

The process of mapping from an input to an output using fuzzy logic is referred to as Fuzzy Inference(reasoning). The steps of this fuzzy reasoning (operations upon fuzzy IF THEN rules) executed through FISs are Fuzzification, Combination of the membership values on the premise phase to achieve firing strength of each of the rules, come up with the qualified consequents (i.e., fuzzy or crisp) or each rule based on the firing strength, and Defuzzification.

\subsection{Adaptive Neuro-Fuzzy Inference System}

The amalgamation of ANN with FLIS (Fuzzy Logic Inference System) produces fuzzy network system. An example of this system is ANFIS, this makes use of ANN to achieve fuzzification, fuzzy inference(reasoning) and defuzzification.
ANFIS uses ANN's learning capability to represent rules from the input/output data pairs. ANFIS differs compared to ANN as the latter make use of the connection weights to present a system while the former uses fuzzy language rules from fuzzy inference. ANFIS makes use of Mamdani and Sugeno fuzzy inference methods.

[5] applied ANFIS to the evaluation of supply chain management. This research documented that construction business has various levels of uncertainty. Series of methodical approach were presented to resolve the issues of uncertainties. However, the best suitable method or approach to solve each problem has to be chosen by the decision makers. The concept of flexibility is needed by construction establishments to overcome uncertainty. The study aimed at evaluating this flexibility in the supply chains. [6] used genetic algorithm to presented various methods to resolving production planning and scheduling problems. The research stated that the challenge of scheduling is linked with the allocation of resources for the purpose of optimization of the function(s) of aim. The need for insightful and efficient methods, flexibility of models which contains optimized solution technique to production planning and control systems motivated the research. Comparison of Simple genetic algorithm and genetic algorithm with niches was carried out and presented. According to this research, Genetic algorithms is often used to solve more real time problems. This is because genetic algorithms have overtime been very effective in resolving problems categorized as hard-solving issues (NPhard).

\section{MODEL}

The conventional system of production planning has overtime been faced with several challenges which include; excessive labour cost, inadequate process flow, additional inventory cost, and inadequate use of production capacity, unnecessary time wastage and delay in deliveries of finished goods. To curb these limitations, this research presents a Neuro-Fuzzy Based Decision Support System for electrical cable production planning. The key components of the framework and their respective descriptions are presented. The architecture of the system is presented in Figure 2.

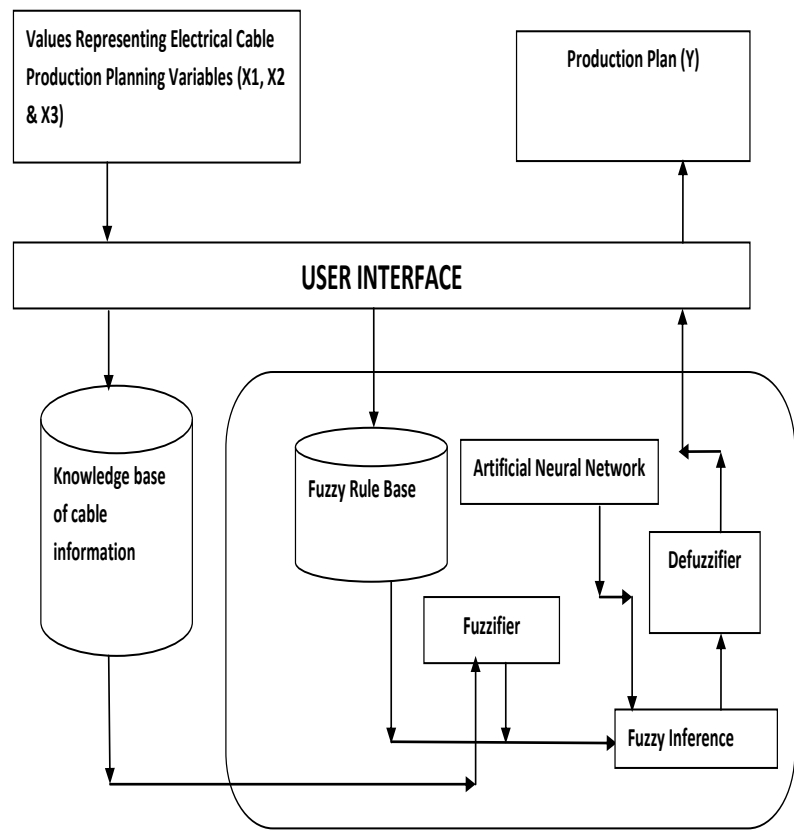

Fig 2: Architecture of the Neuro-Fuzzy Decision Support System for Electrical Cable Production Planning 
The core components of the system as shown in Figure 2 include the User Interface where the users interact with the computer for the purpose of effective operation or control of the neuro-fuzzy system by the user, while there is information feedback by the system which assists user's decision-making process. The database holds information about the various cables available at Coleman Technical industries limited. Such information includes cable type, size, length, colour, amount etc. Fuzzy Inference System includes Fuzzifier, Knowledge Base, Inference Engine, and Defuzzifier.

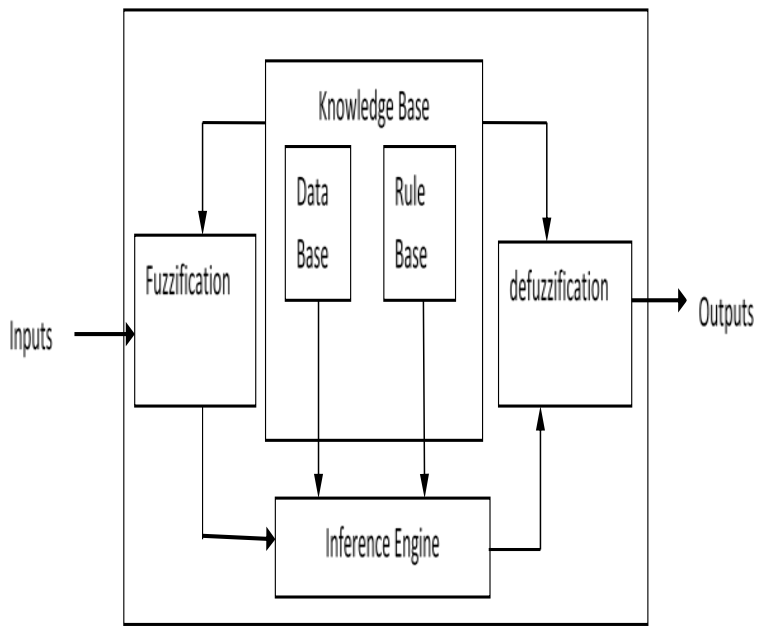

Fig 1: Fuzzy Inference System

The fuzzifier converts the input that holds the values into fuzzy values through its membership functions. For example, let $\mathrm{v}$ be a fuzzy set of electrical cable production planning variables in $\mathrm{v}$ and $x_{i}$ is an element in $\mathrm{v}$ as presented in the equation (3)

$v=\left\{\left(x_{i}, \mu_{v}\left(x_{i}\right)\right) \mid x_{i} \in v, \mu_{v}\left(x_{i}\right) \in[0,1]\right\}$

Where $\mu_{v}\left(x_{i}\right)$ is the membership function of $x_{i}$ in $\mathrm{v}$ and it symbolizes the degree of contribution of $x_{i}$ to the outcome of a particular prediction? In this research, the fuzzy set used to present the attributes of Electrical Cable Production Planning Variables is High, Average and Low. Each attribute as shown in the Table 1 below is presented by a linguistic term belonging to the defined fuzzy set. Each of the linguistic terms has an associated numeric value.

Table 1. Electrical Cable Production Planning Variables

\begin{tabular}{|c|l|l|}
\hline S/N & $\begin{array}{c}\text { PRODUCTION PLANNING } \\
\text { ATTRIBUTES }\end{array}$ & CODE \\
\hline 1 & Quantity Ordered & $\mathrm{X} 1$ \\
\hline 2 & Quantity in Stock & $\mathrm{X} 2$ \\
\hline 3 & Lead Period & $\mathrm{X} 3$ \\
\hline 4 & Production Plan & $\mathrm{Y}$ \\
\hline
\end{tabular}

The input variable lead days has three fuzzy sets namely "High", "Average" and "Low". Fuzzy set range of lead days are recognized in Table 2(below). The membership functions for fuzzy sets are recognized in Table 3.
Table 2. Fuzzy Sets for Lead Days

\begin{tabular}{|l|l|l|}
\hline Input Field & \multicolumn{1}{|c|}{ Range } & \multicolumn{1}{|c|}{ Fuzzy Set } \\
\hline Lead days & $1-3$ & High \\
\cline { 2 - 4 } & $4-6$ & Average \\
\cline { 2 - 3 } & $7-10$ & Low \\
\hline
\end{tabular}

Table 3. Fuzzy Sets for Stock Quantity

\begin{tabular}{|l|l|l|}
\hline Input Field & \multicolumn{1}{|c|}{ Range } & \multicolumn{1}{|c|}{ Fuzzy Set } \\
\hline Stock Quantity & $\begin{array}{l}\text { More than half of } \\
\text { quantity ordered }\end{array}$ & High \\
\cline { 2 - 3 } & $\begin{array}{l}\text { Half of quantity } \\
\text { ordered }\end{array}$ & Average \\
\cline { 2 - 3 } & $\begin{array}{l}\text { Less than half of } \\
\text { quantity ordered }\end{array}$ & Low \\
\hline
\end{tabular}

The rule base for the Electrical Cable Production Planning Decision Support System contains set of IF-THEN rules where the IF and the subsequent THEN comprises linguistic variables. Through the help of production planning experts, the rules making up the rule base are carefully framed. A rule is termed valid if any precedent index such as high, average and low is true, else it is not valid. Example of this rule base is as follows: If (X1 is high) and (X2 low) and (X3 is Average) then (Output is High)

The Inference Engine is the decision-making unit of the Fuzzy Logic System. It accepts inputs from the rule base and the fuzzification interface; it resultantly applies a pre-declared procedure to the inputs for the purpose of producing the expected output.

Defuzzifier transforms fuzzy results of the inference into a crisp output. The experts analyses and interprets this output; this brings about efficient decision making in electrical cable production planning. The defuzzification method used is called the fuzzy mean, where the output is obtained by the mean of each output of the set of rules stored in the knowledge base of the system. The output of the inference engine is received as the input by the interface and it applies equation 4 below to arrive at its output. The fuzzy mean defuzzification method is expressed as

$y=\frac{\sum_{i=1}^{k} \beta_{i} b_{i}}{\sum_{i=1}^{k} \beta_{i}}$

Where $\mathrm{y}$ is the defizzification output, $\beta_{i}$ is the membership of the output of each rule, and $b_{i}$ the mean associated with each rule.

\subsection{Artificial Neural Network (ANN)}

Neural network is designed using hybrid optimization method. This combines the least square estimate (LSE) in the forward pass and the gradient descent method in the backward pass. Each epoch comprises of a forward pass and a backward pass.

\subsubsection{Forward Pass}

The algorithm in the forward pass uses least-squares method to identify the consequent parameters on the layer 4 . 
$\mathrm{F}=\frac{w_{1}}{w_{1}+w_{2}+w_{3}} f_{1}+\cdots+\frac{w_{3}}{w_{1}+w_{2}+w_{3}} f_{1}=\bar{w}_{1} f_{1}+\cdots+\bar{w}_{3}$

$=\left(\bar{w}_{1} x_{1}\right) p_{1}+\left(\bar{w}_{1} x_{2}\right) q_{1}+\cdots+\left(\bar{w}_{1} x_{3}\right) R_{1}+\left(\bar{w}_{1}\right) Y_{1}+$ $\cdots+\left(\bar{w}_{3} x_{1}\right) p_{3}+\left(\bar{w}_{3}\right) Y_{3}$

(6)

Which is linear in the consequent parameters $p_{1}, q_{1}, \ldots, R_{1}, Y_{1}, p_{2}, q_{2}, \ldots, R_{2}$ and $Y_{2}$

$f=R W$

If $X$ matrix is invertible then

$W=R^{-1} f$

$\left(R^{T} R\right)^{-1} R^{T} f$

Otherwise a pseudo-inverse is used to solve for $W$.

\subsubsection{Backward Pass}

Here errors are propagated backward and the premise parameters are updated by gradient descent. When premise parameter values are fixed, the overall output is expressed as a linear combination of the consequent parameters.

$a_{i j}(t+1)=a_{i j}(t)-\frac{\eta}{\rho} \cdot \frac{d f}{d f}$

Where $\eta$ is the learning rate of $a_{i j}$. The chain rule is used in calculation of the partial derivatives used to update the membership functions parameters. $\frac{d E}{d a_{i j}}=\frac{d E}{d f} \cdot \frac{d f}{d f} \cdot \frac{d f_{i}}{d f_{i}} \cdot \frac{d w_{i}}{d w_{i}} \cdot \frac{d u_{i j}}{d u_{i} j}$

We derived partial derivatives as:

$$
\begin{aligned}
& \mathrm{E}=\frac{1}{2}\left(f-f^{1}\right)^{2} \text { hence } \frac{d E}{d f}=\left(f-f^{1}\right)=\theta \\
& f=\sum_{i=1}^{n} f_{1} \text { hence } \frac{d E}{d f}=1
\end{aligned}
$$

$$
\begin{aligned}
f_{i} & =\frac{\left(p_{i} x_{1}+q_{i} x_{2}+r_{i}\right)-f}{y \sum_{i=1}^{n} w_{i}} \\
w_{i} & =\prod_{j=1}^{m} \mu_{A_{i j}} \text { hence } \frac{d w_{i}}{d \mu_{i j}}=\frac{w_{i}}{\mu_{i j}}
\end{aligned}
$$

The final derivative depends on the membership function used. The parameters of the membership functions are updated in the same way. The gradient is then obtained as:

$$
\begin{gathered}
\frac{d E}{d a_{i j}}=\theta \frac{\left(p_{i} x_{1}+q_{i} x_{2}+r_{i}\right)-f}{y \sum_{i=1}^{n} w_{i}} \frac{w_{i}}{d \mu_{i j}} \frac{d \mu_{A_{i j}}}{d a_{i j}} \\
\frac{d E}{d a_{i j}}=\theta \frac{\left(p_{i} x_{1}+q_{i} x_{2}+r_{i}\right)-f}{y \sum_{i=1}^{n} w_{i}} \frac{w_{i}}{d \mu_{i j}} \frac{d \mu_{B_{i j}}}{d b_{i j}}
\end{gathered}
$$

\subsubsection{Neuro-Fuzzy Components}

The block diagram in figure in figure 4 depicts the ANFIS which integrates ANN and FIS components and as well drives the proposed system.

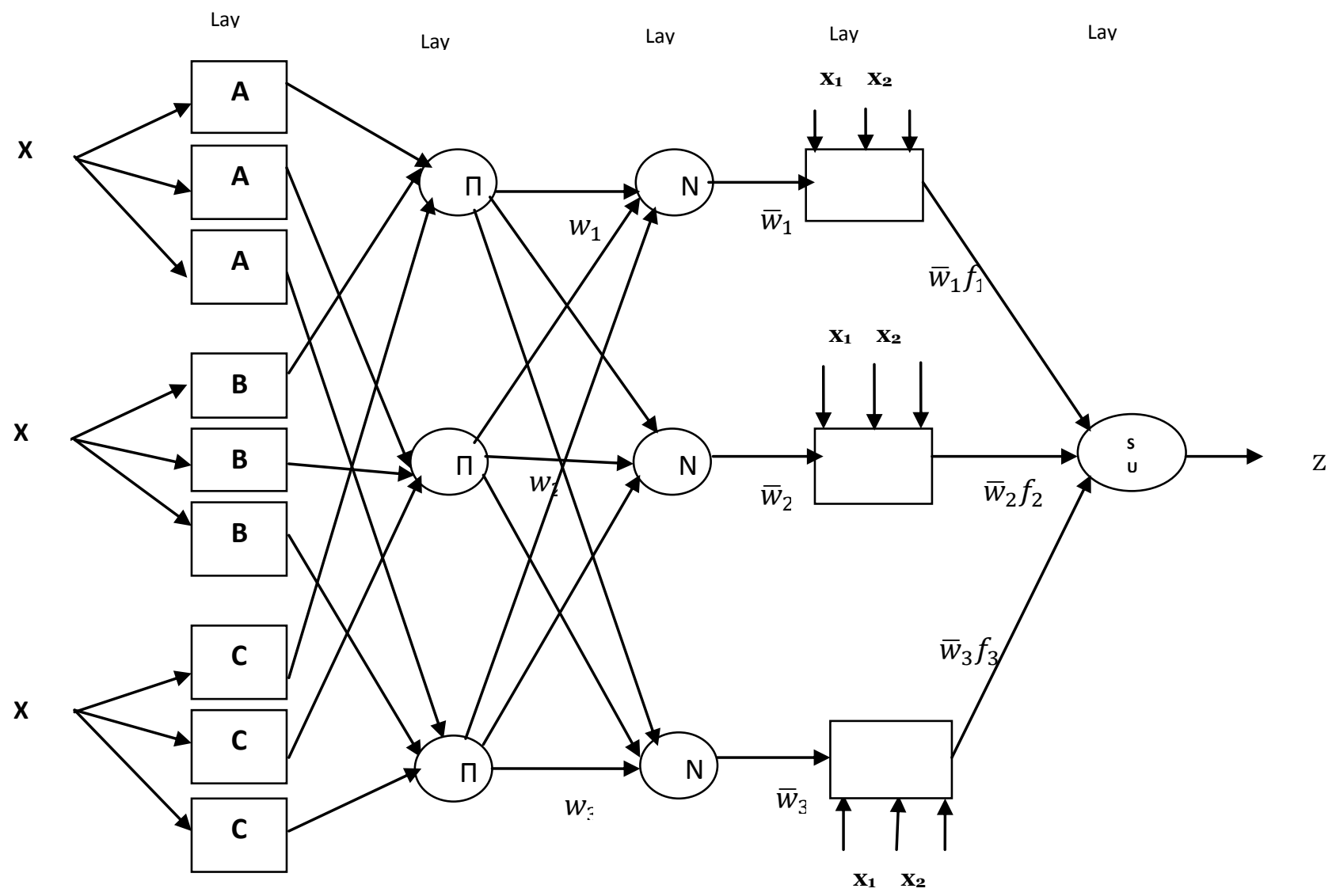

Fig 4: Block diagram: Neuro-fuzzy system for Electrical Production Planning 
Where $X_{1}, X_{2}$ and $X_{3}$ are the variables considered when planning production of various sizes of electrical cables. $\mathrm{A}_{1}$, $\mathrm{A}_{2}$ and $\mathrm{A}_{3}, \mathrm{~B}_{1}, \mathrm{~B}_{2}, \mathrm{~B}_{3} \ldots . . \mathrm{C}_{3}$ are the linguistic variables. The rules used by the ANFIS are based on Takagi-Sugeno's Model and presented as:

$$
\begin{aligned}
& \text { if }\left(x_{1} \text { is } a\right) \text { and }\left(x_{2} \text { is } b\right) \text { and }\left(x_{3} \text { is } c\right) \text { then } \quad Z=p_{i} x_{1}+ \\
& q_{i} x_{1}+r_{i}
\end{aligned}
$$

Where $x_{1}, x_{2}, x_{3}$ are inputs variables, a, b, c are fuzzy sets of the input variables $p_{i}, q_{i}, r_{i}$ are the parameters of dependent variable and $\mathrm{Z}$ is the output.

The entire ANFIS system is made up of five layers, they are:

Layer 1: Every node $\mathrm{i}$ in this layer is an adaptive node with a node function

$$
O_{i}^{1}= \begin{cases}\mu_{A_{i}}(x), & i=1,2 \\ \mu_{B_{i}}(x), & i=1,2 \\ \mu_{C_{i}}(x), & i=1,2\end{cases}
$$

Where $x_{1}, x_{2}$ and $x_{3}$ are the inputs to node $i$ and $A_{i}, B_{i}$ or $C_{i}$ is a linguistic label (High", "Average" and "Low") associated with this node. $O_{i}^{1}$ is the membership grade of the fuzzy set $A_{i}$ and it indicates the degree of membership of the input $x_{1}, x_{2}$ and $x_{3}$. This research adopted the triangular Membership Function (MF) because of its ease of use and it is presented in equation (19).

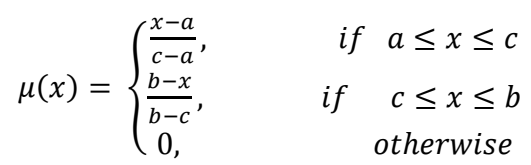

Layer 2: Every node in this layer multiplies the incoming signals and sends the product out. Each node output represents the firing strength of a rule

$$
o_{i}^{2}=W_{i}=\mu_{A_{i}}\left(x_{1}\right) X \mu_{B_{i}}\left(x_{2}\right) X \mu_{C_{i}}\left(x_{3}\right), \quad i=1,2
$$

Layer 3: Every node in this layer is a fixed node labelled N. The $i$ th node calculates the ratio of the $i$ th rule's firing strength to the sum of all rules' firing strengths:

$$
o_{i}^{3}=\overline{W_{i}}=\frac{w_{i}}{w_{1}+w_{2}+w_{3}}, \quad i=1,2
$$

The outputs of this layer are called normalized firing strengths.

Layer 4: Every node $i$ in this layer is an adaptive node with a node function

$$
o_{i}^{4}=\bar{w}_{i} f_{i}=\bar{w}_{i}\left(p_{i} x+q_{i} y+r_{i}\right), \quad i=1,2
$$

where $\bar{w}_{i}$ is the output of Layer 3 , and $\left\{\mathrm{p}_{\mathrm{i}}, \mathrm{q}_{\mathrm{i}}, \mathrm{r}_{\mathrm{i}}\right\}$ are the parameter set. The parameters in this layer are referred to as consequent parameters.

Layer 5: The single node in this layer is a fixed node labelled sum, which computes the overall output as the summation of all incoming signals:

$$
\begin{aligned}
& o_{i}^{5}=\text { overall output }=\sum_{i} \bar{w}_{i} f_{i}=\frac{\sum_{i} w_{i} f_{i}}{\sum_{i} w_{i}} \\
& =\frac{w_{1}}{w_{1}+w_{2}+w_{3}} f_{1}+\frac{w_{2}}{w_{1}+w_{2}+w_{3}} f_{2}+\frac{w_{3}}{w_{1}+w_{2}+w_{3}} f_{3} \\
& =\left(\left(\mathrm{x}_{1} \mathrm{w}_{1}\right) \mathrm{P}_{1}+\left(\mathrm{x}_{2} \mathrm{w}_{1}\right) \mathrm{Q}_{1}\right)+\left(\mathrm{x}_{3} \mathrm{~W}_{1}\right) \mathrm{X}_{1}+\left(\mathrm{w}_{1}\right) \mathrm{Y}_{1}+\ldots+\left(\mathrm{x}_{3} \mathrm{~W}_{3}\right) \mathrm{X}_{3}+\left(\mathrm{w}_{3}\right) \\
& \mathrm{Y}_{3}
\end{aligned}
$$

The performance of the decision making model is evaluated using Root Mean Square Error. It is a suitable indicator that describes the discrepancy between actual and predicted result. RMSE is calculated as:

$\operatorname{RMSE}=\sqrt{\frac{\sum_{i=1}^{n}\left(p_{i}-o_{i}\right)^{2}}{n}}$

Where $n$ is the number of data is pairs, $p_{(i)}$ and $o_{(i)}$ are $i^{\text {th }}$ desired output and predicted output respectively. The final output of the Neuro-Fuzzy system represents the suggested result of the decision-making model stating the amount of cables to be produced.

\section{IMPLEMENTATION}

Here, we discuss the implementation and testing of a Neurofuzzy Decision Support System for electrical cable production planning using dataset of cooperate customers and distributors' order from Coleman Technical industries Limited (CTIL) received between $22^{\text {nd }}$ and $31^{\text {st }}$ of January, 2018. The system is aimed at assisting Managers in deciding how much cables to produce in order to fulfill customer orders, how much of raw materials to request from suppliers and the

\begin{tabular}{|c|c|c|c|c|c|}
\hline & & X1 & X2 & X3 & $\mathbf{Y}$ \\
\hline $\begin{array}{l}1 \underset{\mathrm{X}}{\mathrm{X}} 1.5 \mathrm{~mm}^{2} \\
(\mathrm{NCY}) \mathrm{R}\end{array}$ & Coils & 420 & 150 & 2 & 504 \\
\hline $\begin{array}{lcc}1 \quad \mathrm{X} & 1.5 \mathrm{~mm}^{2} \\
(\mathrm{NCY}) \mathrm{G} & \end{array}$ & Coils & 512 & 121 & 2 & 614 \\
\hline . & . & . & . & . & . \\
\hline . & . & . & . & . & . \\
\hline & . & . & . & . & . \\
\hline $\begin{array}{l}4 \quad \mathrm{X} \\
10 \mathrm{~mm}^{2}(\mathrm{NCYRY})\end{array}$ & Coils & 10 & 4 & 1 & 12 \\
\hline
\end{tabular}
delivery period. It also presents the tools used in achieving the implementation and evaluation.

\subsection{Experiments and Results}

Three hundred and ten (310) customer's orders containing house wiring cables were collected. 185 were used for training, 78 for testing and 47 for validation. Input variables (X1 to X3) were considered for each record. Table 4, 5 and 6 shows the dataset used.

Table 4. Exported Training Data from Excel into the Matlab Interface 
Table 5. Exported Testing Data from Excel environment into the Matlab Workspace

\begin{tabular}{|c|c|c|c|c|c|}
\hline & & X1 & $\mathbf{X} 2$ & $\mathbf{X 3}$ & $\mathbf{Y}$ \\
\hline $\begin{array}{lr}4 & X \\
70 \mathrm{~mm}^{2}(\mathrm{NCYRY}) \\
\end{array}$ & Coils & 13 & 9 & 2 & 13 \\
\hline $\begin{array}{lcc}1 & \mathrm{X} & 2 \mathrm{~mm}^{2} \\
(\mathrm{NCY}) \mathrm{R} & \end{array}$ & Coils & 255 & 99 & 1 & 306 \\
\hline $\begin{array}{lcc}1 & \mathrm{X} & 2 \mathrm{~mm}^{2} \\
(\mathrm{NCY}) \mathrm{Y} & \\
\end{array}$ & Coils & 252 & 140 & 2 & 252 \\
\hline . & . & . & . & . & . \\
\hline . & . & . & . & . & . \\
\hline . & . & . & . & . & . \\
\hline 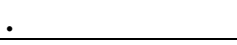 & . & . & - & • & . \\
\hline $\begin{array}{lr}3 & \mathrm{X} \\
6 \mathrm{~mm}^{2}(\mathrm{NCYY}-\mathrm{F})\end{array}$ & Coils & 9 & 4 & 2 & 11 \\
\hline
\end{tabular}

Table 6. Validation Data

\begin{tabular}{|l|l|l|l|l|l|}
\hline & & X1 & X2 & X3 & X4 \\
\hline $\begin{array}{l}1.5 \mathrm{~mm}^{2} \text { X } \\
(\mathrm{NCY}) \mathrm{R}\end{array}$ & Coils & 448 & 73 & 1 & 538 \\
\hline $\begin{array}{l}1.5 \mathrm{~mm}^{2} \mathrm{X} \\
(\mathrm{NCY}) \mathrm{BL}\end{array}$ & Coils & 262 & 59 & 1 & 314 \\
\hline $\begin{array}{l}1 \\
2.5 \mathrm{~mm}^{2} \\
(\mathrm{NCY}) \mathrm{G}\end{array}$ & Coils & 162 & 43 & 1 & 194 \\
\hline. &. &. &. &. &. \\
\hline. &. &. &. &. &. \\
\hline. &. &. &. &. \\
\hline $\begin{array}{l}1 \\
2.5 \mathrm{~mm}^{2} \\
(\mathrm{NCY}) \mathrm{R}\end{array}$ & Coils & 476 & 232 & 1 & 571 \\
\hline
\end{tabular}

\subsubsection{Fuzzy Inference System Module}

The developed FIS Module for Electrical Cable Production Planning is shown in figure 5. It consists of three input variable X1 to X3, an intermediate variable Decision Support System for Electric Cable Production Planning (DSSECPP) and the output variable $f(u)$ which suggest the amount of a particular cable size to be produced.

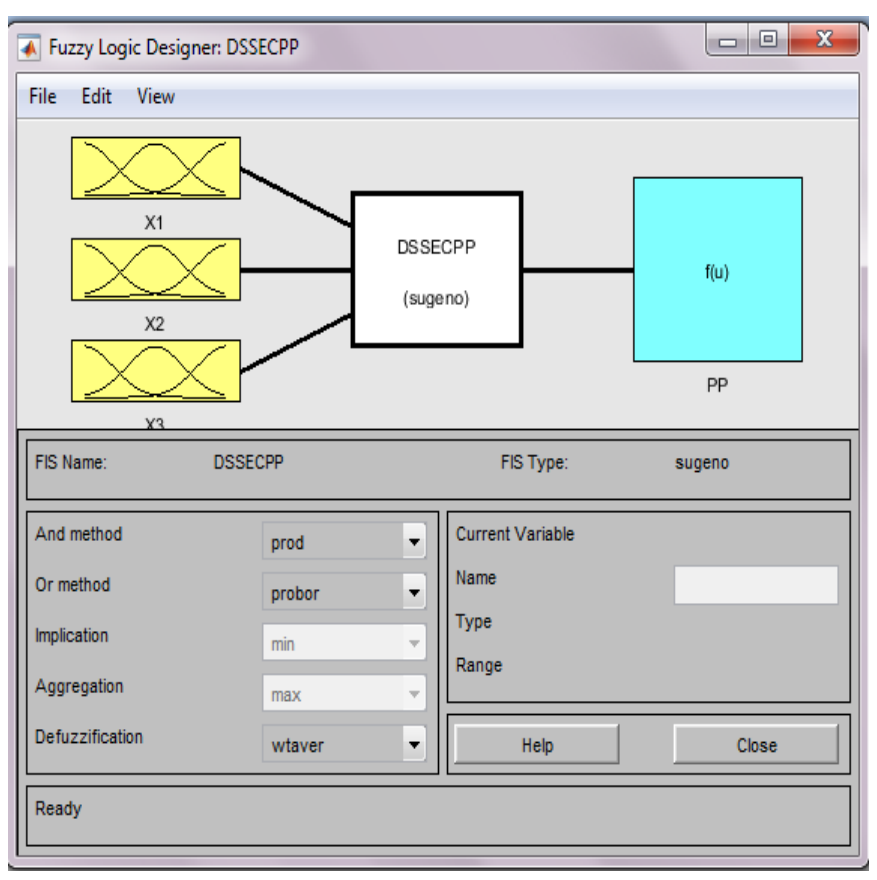

Fig 5: Fuzzy Inference System (FIS) Module

\subsubsection{Membership Function Module}

The module defines the membership functions associated with all input and output variables. The membership function of the proposed system is shown in figure 6 .

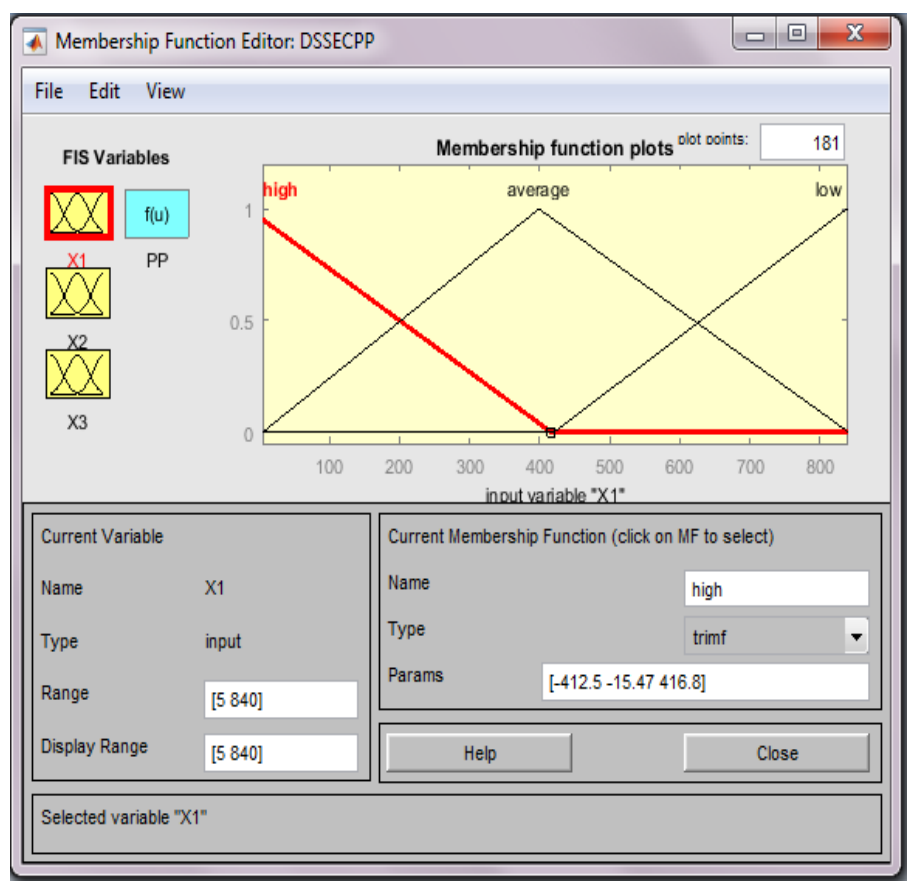

Fig 6: Membership Function

\subsubsection{Fuzzy Rule Base}

Figure 8 presents the Fuzzy Rule Base of the system. This module provides a way of representing all rules that defines the behavior of the FIS. The rule base is made of rules obtained from experts in the field of electrical cable production. Each rule consists of three (3) input variables and one (1) output variable. 


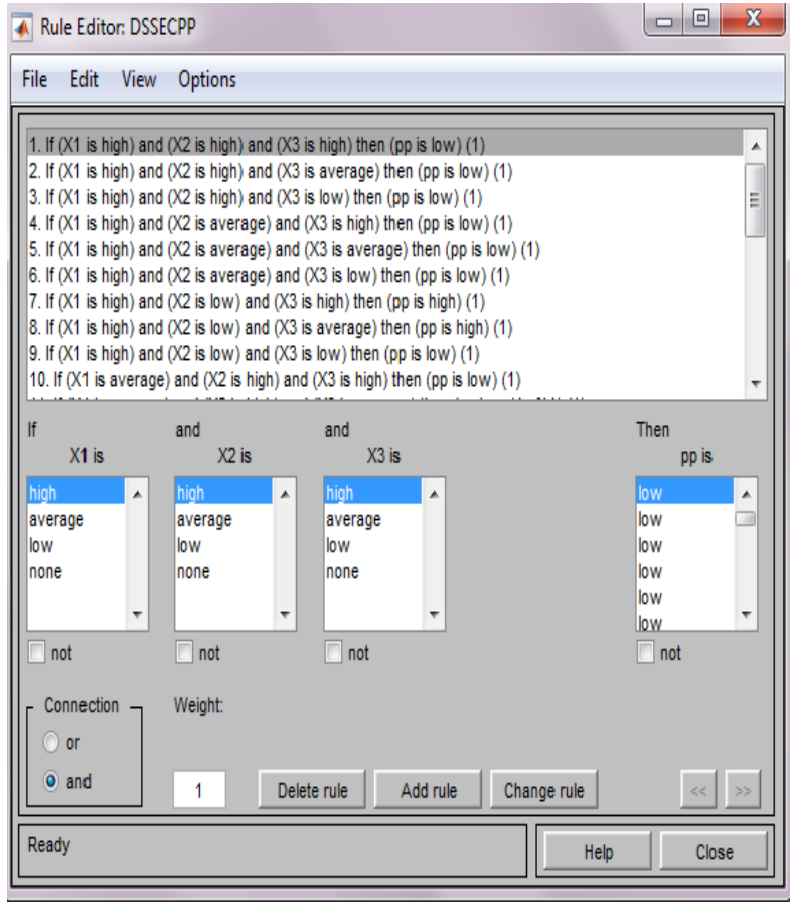

Fig 8 Fuzzy Rule Base of DSS for Electrical Cable Production Planning

\subsubsection{Fuzzy Rule Viewer Module of DSSECPP}

This module shows the interpretation of the entire fuzzy inference process and it is presented in Figure 9. It allows the user to enter values for the variables X1 to X3 of Electrical Cable Production Planning for a particular size of cable and on pressing the enter key, the amount to be produced is suggested.

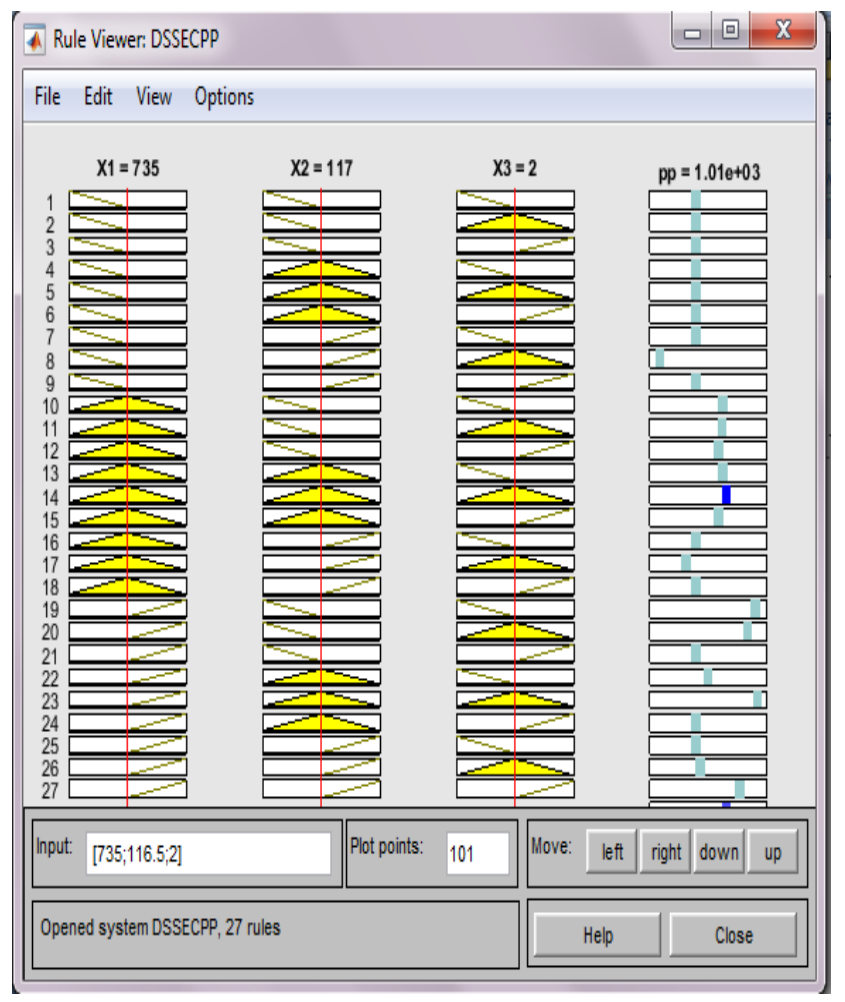

Fig 9: Fuzzy Rule Viewer Module of DSSECPP
Decision Support System for Electrical Cable Production Planning Neuro Fuzzy Structure

Figure 10 presents the structure of the DSS for Electrical Cable Production Planning. This has five layers. It has three input values and one output. The first layer has the input values while the second, third, fourth and fifth layers are hidden layers of ANFIS where several computations are performed in order to suggest the amount of a particular size of cable to be produced.

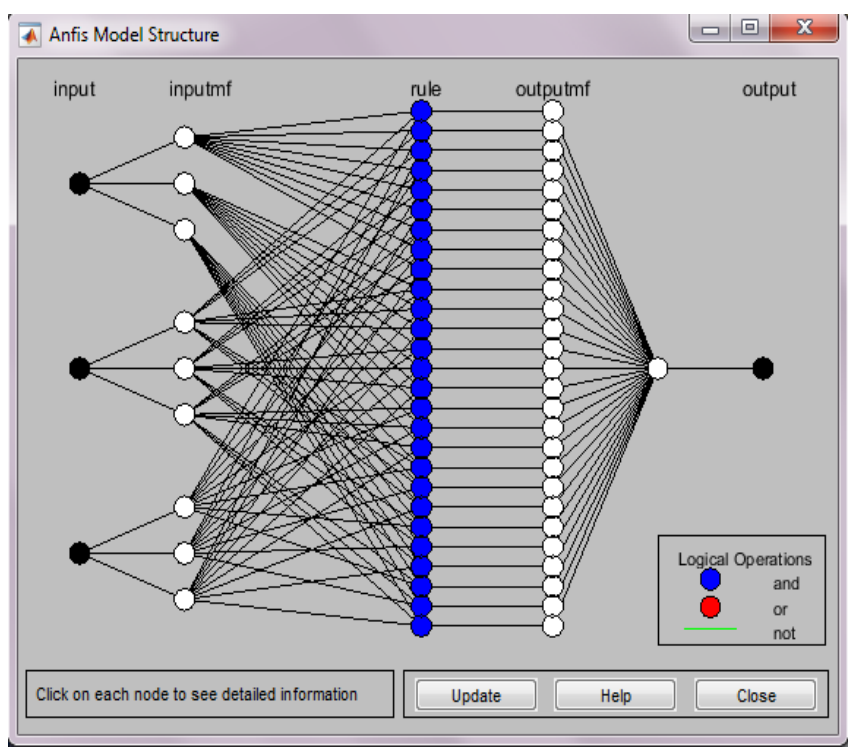

Fig 10: Structure of DSS for Electrical Cable Production Planning

\subsubsection{Neuro-Fuzzy Training, Testing and Validation Sessions}

Figures 11, 12 and 13 shows the training, testing and validation results using the datasets.

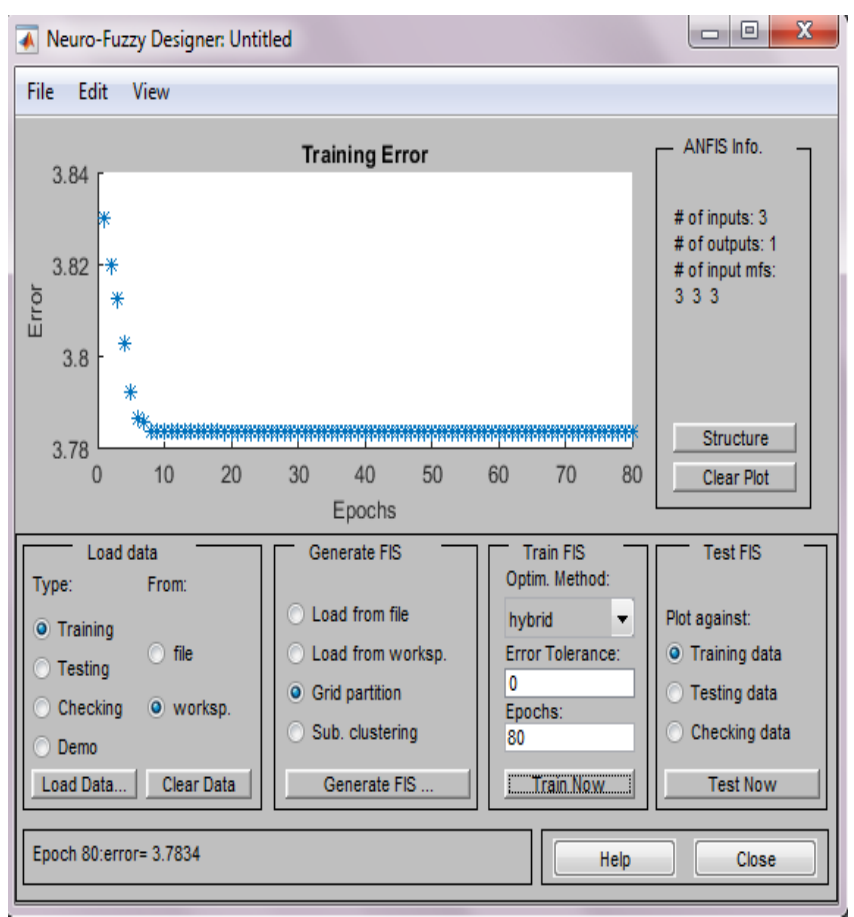

Fig 11: Pictorial view of the output of training session 


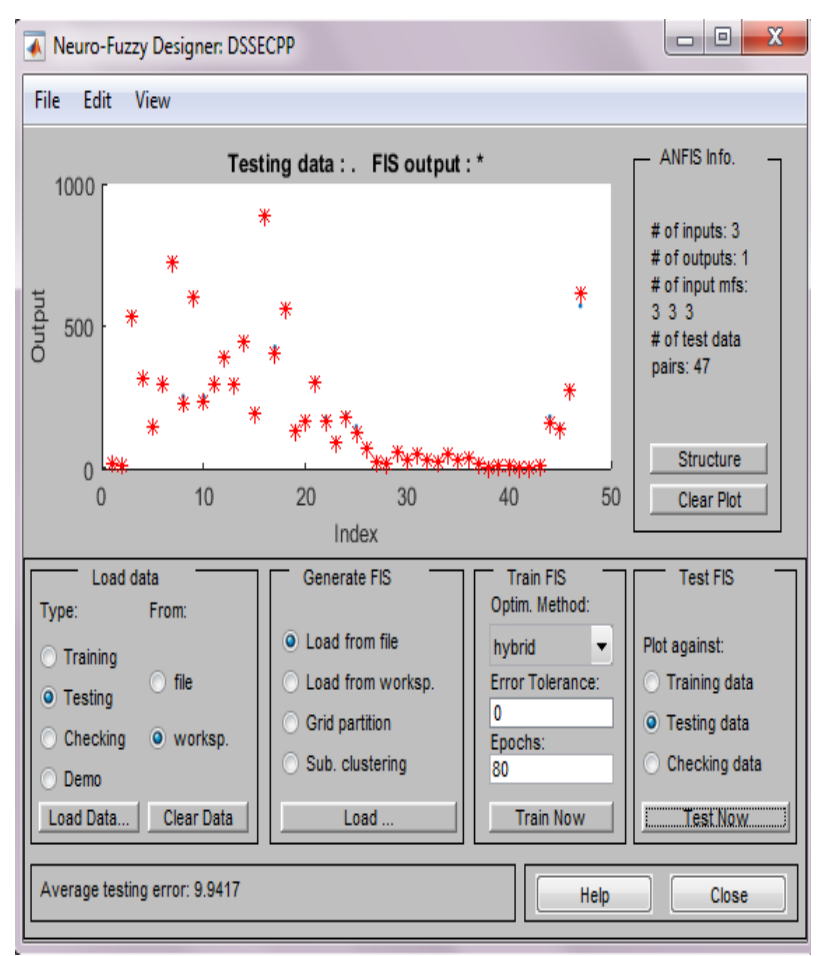

Fig 12: Outcome of Testing Session

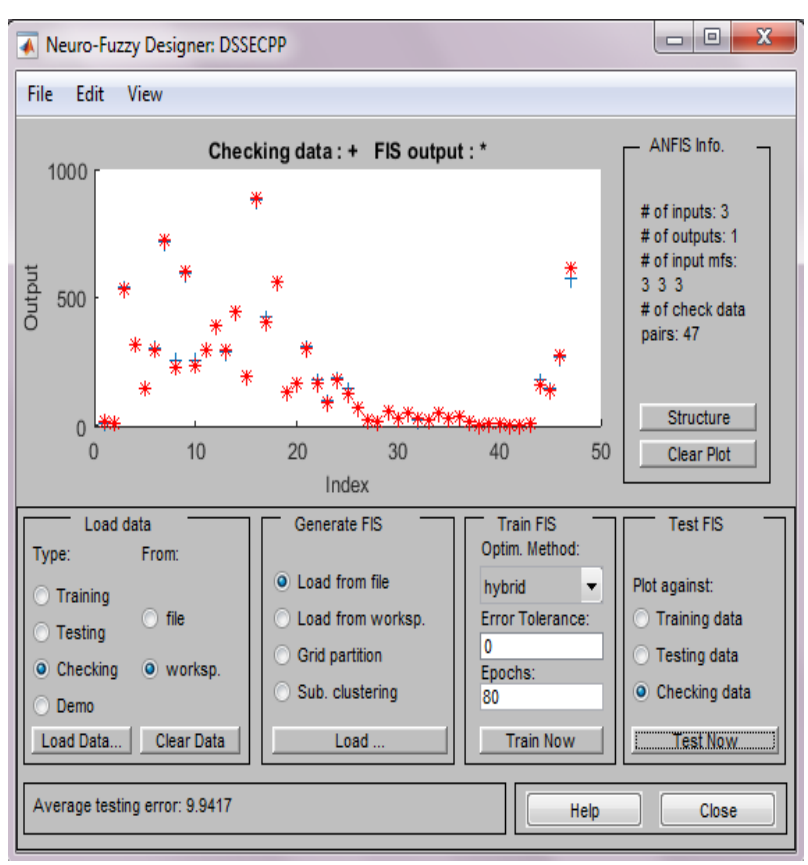

Fig 13: Outcome of Validation Session

A total of 310 dataset was used in this research. 185 were used for training, 78 for testing and 47 for validation of the system. The average testing error was $9.9417 \%$, accuracy of $90.06 \%$.

\section{SYSTEM EVALUATION}

The efficiency of the proposed system is examined by comparing the results of the Decision Support System for Electrical Cable Production Planning (DSSECPP) with a production plan obtained from an artificial neural network model as shown in Table 7.

Table 7: Comparison of Production Plan of DSSECPP and ANN

\begin{tabular}{|c|c|c|c|c|c|c|c|c|}
\hline $\mathbf{S} / \mathbf{N}$ & $\mathrm{X} 1$ & $\mathrm{X} 2$ & $\mathrm{X3}$ & $\mathbf{Y}$ & RANN & RANFIS & $\begin{array}{l}\text { ER_ANN } \\
\text { [RCA-RNN] }\end{array}$ & $\begin{array}{l}\text { ER_ANFIS } \\
\text { [RCA-RANFIS] }\end{array}$ \\
\hline 1 & 270 & 74 & 1 & 324 & 323 & 327 & 1 & 3 \\
\hline 2 & 23 & 12 & 1 & 23 & 25 & 25 & 2 & 2 \\
\hline 3 & 610 & 412 & 2 & 610 & 610 & 610 & 0 & 0 \\
\hline 4 & 549 & 132 & 2 & 659 & 663 & 659 & 4 & 0 \\
\hline 5 & 142 & 39 & 2 & 170 & 170 & 170 & 0 & 1 \\
\hline 6 & 199 & 101 & 3 & 199 & 201 & 199 & 2 & 0 \\
\hline 7 & 544 & 160 & 1 & 653 & 657 & 655 & 4 & 2 \\
\hline 8 & 27 & 15 & 3 & 27 & 26 & 27 & 1 & 0 \\
\hline 9 & 120 & 48 & 1 & 144 & 139 & 138 & 5 & 6 \\
\hline 10 & 44 & 11 & 2 & 53 & 53 & 52 & 0 & 1 \\
\hline
\end{tabular}


$\mathrm{X} 1=$ Order Amount $\mathrm{X} 2=$ Amount in Store X3= Lead Days $\mathrm{Y}=$ Result of Convectional Approach $\mathrm{RANN}=$ Result of Artificial Neural Network RANFIS= Result from ANFIS

$\mathrm{RMSE}=\sqrt{\frac{\sum_{i=1}^{n}\left(p_{i}-o_{i}\right)^{2}}{n}}$

$$
\begin{aligned}
& \text { RMSE }(\text { ANN })=6.0 \\
& \operatorname{RMSE}(\text { ANFIS })=4.7 \\
& \operatorname{RMSE}(\text { ANFIS })-\operatorname{RMSE}(\text { ANN })=1.3
\end{aligned}
$$

From the results of the RMSE (above), The proposed ANFIS model presents a better result than the ANN approach for planning of electrical cable production.

\section{CONCLUSION}

One of the major challenges faced by manufacturing companies in Nigeria is the inability to produce goods and services in their right proportions per demand and per time; which has led to unstable production pattern such as under or over production, and its resultant price dwindle, therefore the need for proper production planning which includes the decision on the amount of each size of cable to be produced in order to meet customer demands and deadlines.

Production Planning and overcoming its ensuing challenges has overtime become an evolving research area in the field of management sciences. It spans a wide range of decisions in a manufacturing organization. The decisions can be long term, medium term or short term, depending on the duration of time from planning to final execution of the decision.

Appropriate decision on the amount of cables to be produced will help in cost reduction and improve efficiency. In this approach, decision on amount of cables to produce is based on customer order, stock level and lead days. The convention approach suffers from a varying number of factors such as lack of skilled employees, large amount of customer orders and unplanned orders received from walk-in customers. In order to reduce the potential risk associated with production planning, improved technology techniques must be put in place.

In this research, the concepts of Neural Networks (NN) and Adaptive Neuro Fuzzy Inference Systems (ANFIS) were extensively explored. A Neuro Fuzzy Decision Support System for Electrical Cable Production Planning was developed having the capabilities of reducing the risks associated with cable production planning. The proposed system functionality was tested using 310 customer orders collected from Coleman Technical Industries Limited and its efficiency was evaluated using standard statistical procedure. From the evaluation results, the Artificial Neural Network gives an error of $1.34 \%$ in making cable production planning decisions while the hybrid system gives an error of $1.18 \%$ in making cable production planning decisions.

Many businesses including manufacturing are reluctant to embrace information technology innovations due to tight budgets. Finance directors are looking for rapid return on investment. Meanwhile, complex infrastructure that no longer fit the purpose is a problem for many organizations though they are unwilling to make changes unless they are convinced that the alternative is better. A Decision Support System (DSS) unlike an Expert System (ES) doesn't replace the human decision maker but rather supports him in carrying out his duty more efficiently. Therefore, the system developed in this research should be seen by managers and other decision making personnel in the cable production industry as a tool which can act as a standalone system or add-on to an existing system to help them perform their functions more efficiently with little financial demand. However, inclusion of indices like machine capacity, raw products and human resource index are suggested in future research. This research presents an efficient Neuro-fuzzy Inference System based DSS for electrical cable production planning.

\section{REFERENCES}

[1] Bansal, S., Vashiath, Y. and Batra, U. (2015), Production Planning. Journal of Computer Science and Engineering. $1(5), 53-57$.

[2] Galina, S. and Sławomir, P. (2009), Intelligent Manufacturing Systems, International Book Series "Information Science and Computing", 142 - 149.

[3] Cirovic, I., Simeonov, S., Stano, P., and Pfaff, O., (2011), Approaches for Solving Production Planning and Scheduling Problems Using Genetic Algorithms. International DAAAM Symposium, 22(1), 0771 - 0772.

[4] Suparta, W., and Alhasa K., (2016), Modeling of Tropospheric Delays Using ANFIS. SpringerBriefs in Meteorology, DOI 10.1007/978-3-319-28437-8_2, 5 18.

[5] Thipparat, T., (2012), Implementations/Application of Adaptive Neuro-Fuzzy Inference System in Supply Chain Management Evaluation. Application of Adaptive Neuro Fuzzy, Fuzzy Logic - Algorithms, Techniques and Implementations, 115 - 126.

[6] Efendigil, T., Onut, S. and Kahraman, C. (2008), A decision support system for demand forecasting with artificial neural networks and neuro-fuzzy models. Expert Systems with Applications, 1 - 11.

[7] Abdel-Aleem, A., El-Sharief, M., Hassan, M., and ElSebaie M. (2017), Implementation of Fuzzy and Adaptive Neuro-Fuzzy Inference Systems in Optimization of Production Inventory Problem. Applied Mathematics and Information Sciences Journal 2 (1), $289-29$.

[8] Akindipe, O. (2014), The Role of Raw Material Management In Production Operations. International Journal of Managing Value and Supply Chains (IJMVSC) 5 (3), 37 - 44.

[9] Amol, G., Harri H. and Pekka K. (2011), Production Planning Through Customized ERP at a Nordic Manufacturing Company. Journal of Enterprise Information Management, 6 (3), 211 - 223.

[10] Ashwini, A., and Keswani, P., (2014), Scheduling By Using Fuzzy Logic in Manufacturing. Int. Journal of Engineering Research and Applications, 4(7), 104-111.

[11] Azizi, A., Yazid, A., Ali, and Ping, W. (2013), An Adaptive Neuro-fuzzy Inference System for A Dynamic Production Environment Under Uncertainties. World Applied Sciences Journal, 25 (3), 428 - 433.

[12] Boran, F., Genc, S., Kurt, M., and Akay D. (2009), A Multi-Criteria Intuitionistic Fuzzy Group Decision Making for Supplier Selection with Topsis Method. Expert Systems with Applications 36 (1), 11363 - 11368.

[13] Bubeník, P. and Horák, F. (2014), Knowledge-Based 
Systems to Support Production Planning. Sustavi temeljeni na znanju kao podrška planiranju proizvodnje, 21(3), $505-509$.

[14] Burduk, A., (2013), Artificial Neural Networks as Tools for Controlling Production Systems and Ensuring Their Stability. International Conference on Information

[15] Abdel-Aleem, A., El-Sharief, M., Hassan, M., and ElSebaie M. (2017), Implementation of Fuzzy and Adaptive Neuro-Fuzzy Inference Systems in Optimization of Production Inventory Problem. Applied Mathematics and Information Sciences Journal 2 (1), $289-29$.

[16] Akindipe, O. (2014), The Role Of Raw Material Management In Production Operations. International Journal of Managing Value and Supply Chains (IJMVSC) 5 (3), $37-44$.

[17] Amol, G., Harri H. and Pekka K. (2011), Production Planning Through Customized ERP at a Nordic Manufacturing Company. Journal of Enterprise Information Management, 6 (3), 211 - 223.

[18] Ashwini, A., and Keswani, P., (2014), Scheduling By Using Fuzzy Logic in Manufacturing. Int. Journal of Engineering Research and Applications, 4(7), 104-111.

[19] Azizi, A., Yazid, A., Ali, and Ping, W. (2013), An Adaptive Neuro-fuzzy Inference System for A Dynamic Production Environment Under Uncertainties. World Applied Sciences Journal, 25 (3), 428 - 433.

[20] Bansal, S., Vashiath, Y. and Batra, U. (2015), Production Planning. Journal of Computer Science and Engineering. $1(5), 53-57$.

[21] Boran, F., Genc, S., Kurt, M., and Akay D. (2009), A Multi-Criteria Intuitionistic Fuzzy Group Decision Making for Supplier Selection with Topsis Method. Expert Systems with Applications 36 (1), 11363 - 11368.

[22] Bubeník, P. and Horák, F. (2014), Knowledge-Based Systems to Support Production Planning. Sustavi temeljeni na znanju kao podrška planiranju proizvodnje, 21(3), $505-509$.

[23] Burduk, A., (2013), Artificial Neural Networks as Tools for Controlling Production Systems and Ensuring Their Stability. International Conference on Information Systems and Industrial Management (CISIM), 12 (45), 487 - 498.

[24] Carmignani, G., Passacantando $\mathrm{M}$ and Tumminelli G. (2014), A Novel Method Based on Artificial Neural Network to Production Planning: a case study of a paints producer. 1-14

[25] Chakrabortty, R., and Hasin, A., (2013), Solving an Aggregate Production Planning Problem By Fuzzy Based Genetic Algorithm (Fbga) Approach. International Journal of Fuzzy Logic Systems (IJFLS), 3(1), 1 - 16.

[26] Eraslan, E. (2009), The Estimation of Product Standard
Time by Artificial Neural Networks in the Molding Industry. Mathematical Problems in Engineering, 2009 (527452), 1 - 12.

[27] Erdem, A. and Gocen, E. (2012), a decision support system for supplier evaluation and order allocation. Expert Systems with Applications, 39 (1), 4927 - 4937.

[28] Filip, F., Zamfirescu, B. and Ciurea C. (2017), Computer-Supported Collaborative Decision- Making, Automation, Collaboration, \& E-Services, 4, DOI 10.1007/978-3-319-47221-8_2, $31-69$.

[29] Huang, H. (2009), Designing a Knowledge-Based System For Strategic Planning: A balanced scorecard perspective. Expert Systems with Applications, 36 (1). 209-218.

[30] Marek, J. and Roger R. (2002), Decision Support Systems. Encyclopedia of Library and Information Science, $1-15$

[31] Moore, G., Electric Cables Handbook/BICC Cables. Third Edition, 23 - 125

[32] Németh, P., Ladinig, T., and Ferenczi, B. (2016), Use of Artificial Neural Networks in the Production Control of Small Batch Production. International Conference on Artificial Intelligence, 237 - 240.

[33] Pranolo, A., In'ammurrohman, F., Hendriana, Y., and Octaviani D. (2015), A Decision Support System using ANFIS to Determine the Major of Prospective Students in A Vocational School of Indonesia. International Journal of Computer Trends and Technology (IJCTT,) 27 (2), $100-105$.

[34] Power, D.J., (2007), A Brief History of Decision Support Systems. http://DSSResources.COM/history/dsshistory.html.

[35] Rakesh, P., Imtiyaz, K., and Ghosh, M., (2014), Linking the Production Planning and Supply Chain Using Fuzzy Logic: An Integrated Model For FMCG Products. International Journal of Engineering Research and Development, 10(10), 33 - 43.

[36] Ramlan, R., and Cheng, A., (2016), The Conceptual Framework of Production Planning Optimisation Using Fuzzy Inference System with Tsukamoto. International Journal of Industrial Management (IJIM) 2(1), 80 - 91.

[37] Rippel, D., Harjes, F., and Scholz-Reiter B., (2010), Modeling a Neural Network Based Control for Autonomous Production Systems. 1- 6.

[38] Sharma, R., and Sinha A., (2012), A Production Planning Model Using Fuzzy Neural Network. International Journal of Computer Applications, 40(4), 19 - 22.

[39] Simeunović, N., Kamenko, I., Bugarski, V., Jovanović, M., and Lalić, B., (2017), Improving Workforce Scheduling Using Artificial Neural Networks Model. Advances in Production Engineering \& Management, 12(4), $337-352$ 